\title{
An extrusion simulation of an aluminum profile by porthole die
}

\author{
Önder Ayer ${ }^{1}$, Sedat Bingöl ${ }^{2}$, İsmail Karakaya ${ }^{3}$ \\ ${ }^{1}$ Trakya University, Edirne, Turkey \\ ${ }^{2}$ Dicle University, Diyarbakir, Turkey \\ ${ }^{3}$ eksenAL Aluminum Extrusion Die Factory, Istanbul, Turkey \\ ${ }^{1}$ Corresponding author \\ E-mail: ${ }^{1}$ onderayer@trakya.edu.tr, ${ }^{2}$ sbingol@dicle.edu.tr, ${ }^{3}$ karakaya@eksenal.com \\ Received 21 August 2019; accepted 28 August 2019 \\ DOI https://doi.org/10.21595/vp.2019.20958 \\ Check for updates \\ Copyright (C) 2019 Önder Ayer, et al. This is an open access article distributed under the Creative Commons Attribution License, which \\ permits unrestricted use, distribution, and reproduction in any medium, provided the original work is properly cited.
}

\begin{abstract}
The aluminum alloys are ideal material because of their corrosion resistance, recycling ability, high specific strength and especially low density for lightweight structures of transportation, aerospace, automotive industries. Hot extrusion process is the most used metal forming method for obtaining a variety of aluminum alloy profiles. The demand for large cross section, multi cavity and thin wall profiles has been increasing with the development of the industry and extrusion method is key solution for producing complex profiles with high productivity. These profiles are generally extruded by porthole dies. The extrusion process by porthole die is complicated and die design has great importance for the quality of the extruded product. Design of the porthole die should give optimum material flow and homogenous temperature distribution both for obtaining desired profile and eliminating die scrap. The measuring the temperature and material flow is not possible for closed die formation and it is so important to estimate both material flow, temperature change in the die. For this aim, an extrusion simulation of a porthole die for standard aluminum profile was investigated in this study with the support of HyperXtrude Inspire Extrude Metal 2019 software, which is specialized for FEM calculations of extrusion process. Each step of extrusion process was simulated. Aluminum AA6063 material was used for simulations, the process temperature was $4500{ }^{\circ} \mathrm{C}$ and punch velocity was selected as $5 \mathrm{~mm} / \mathrm{sec}$. Finally, the FEM results were obtained and the temperature distribution, pressure distribution, billet interface and relative die exit speed results were analyzed.
\end{abstract}

Keywords: extrusion method, porthole die, FEM, aluminum 6063.

\section{Introduction}

The aluminum alloys are ideal material because of their corrosion resistance, recycling ability, high specific strength and especially low density for lightweight structures of transportation, aerospace, automotive industries. These industries require intricate shapes, large cross sections, multi cavity and thin wall profiles. Hot extrusion process is the general used metal forming method for obtaining a variety of aluminum alloy profiles with high productivity. These profiles are generally extruded by porthole dies. The extrusion process by porthole die is complicated and die design phase has great importance for the quality of the extruded product. Design of the porthole die should give optimum material flow and homogenous temperature distribution both for obtaining desired profile and eliminating die scrap. There are number of studies concerning extrusion process using porthole dies. Yu et al. [1] investigated the microstructural changes of the product obtained from porthole dies. Some researchers [2-6] studied on the weld quality of the extruded product. Jie et al. [7] studied on extrusion defects and optimized material flow for the porthole dies. For this aim, they used FEM method and experimental techniques. Qamar et al. [8] investigated repairable die defects and related die correction operations in metal extrusion. They made a list of definition for defects and their causes, preventive measures, and die correction operations. Liu et al. [9] was carried out simulations by HyperXtrude on the extrusion process by porthole dies. They proposed die structure modifications for aluminum profiles with small cavity. 


\section{Material and methods}

In this study, an extrusion simulation of a porthole die for standard box profile was investigated with the support of HyperXtrude Inspire Extrude Metal 2019 software based on ALE formulation, which is specialized for FEM calculations of extrusion process. The main aim was to obtain the pressure and temperature distribution in the process for better product quality and longer die service life since there are few related studies to be referred for practical applications. So, each step of extrusion process was simulated to obtain valuable results to give foresight to the extrusion manufacturers to eliminate the wasting resources at the trial and error phase. Moreover, the billet interface and relative die exit speed results were analyzed. Aluminum AA6063 material was used for simulations, billet diameter was $\varnothing 220 \mathrm{~mm}$ and billet length was $700 \mathrm{~mm}$, butt length was selected as $25 \mathrm{~mm}$. Billet temperature was selected as $450{ }^{\circ} \mathrm{C}$. and punch velocity was set to $5 \mathrm{~mm} / \mathrm{s}$ to realize production conditions. The Coulomb friction model was used for the model and its value was assumed as 0.3 at the die bearing zone. The tetragonal mesh distribution was applied to the model for more accurate results. A standard box profile with the extrusion ratio of 127 was used for the FEM model.

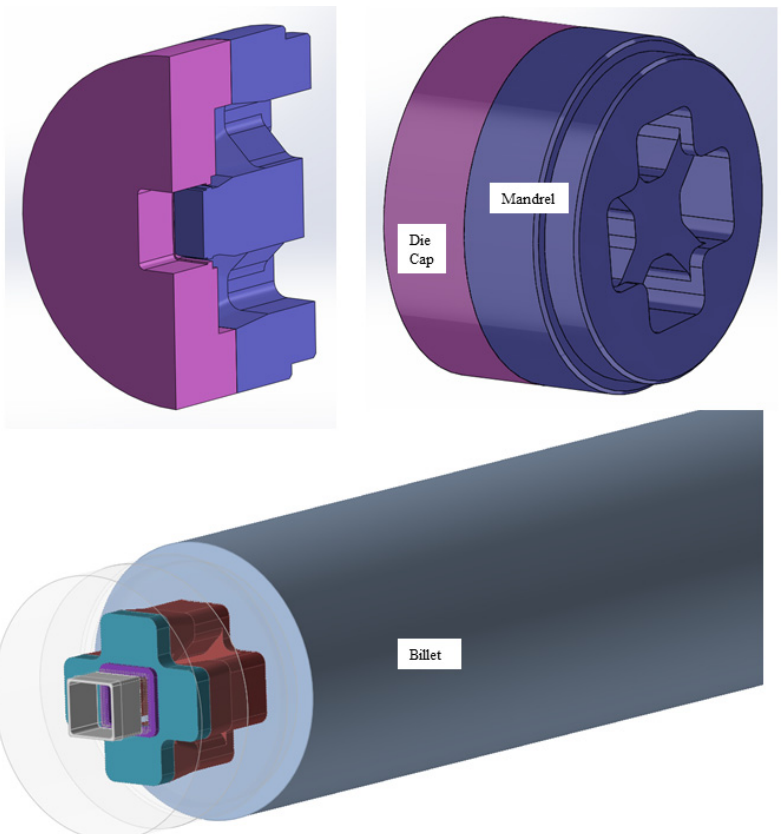

Fig. 1. A diagram for extrusion porthole die

The extrusion is a process which is the material is forced into the die to obtain the desired shape of the product. The number of structural profiles can be produced by extrusion process and the hot extrusion by porthole die is preferred by manufacturers especially for the complicated and hollow sections. Fig. 1 shows the diagram of porthole die for the selected hollow profile. It can be seen from the figure that the mandrel part of the die has 4 portholes. Main features are bearing, pocket, weld chamber and the porthole which were given in Fig. 2 in detail. The material is forced to flow into portholes around the bridges. The portholes balance the metal flow with the suitable distribution and the separated streams flow through the ports and enters the welding chamber. The welding chamber provides enough volume for material to reweld before the die bearing section. Welding chamber are generally preferred for extrusion of softer alloys. Producing hollow sections with longer length, thin hollow sections are the advantages of these type of extrusion dies. The pocket section is selected for hollow profiles to combine the metal flow before it enters die bearing 
section. The bearing section gives the profile in the desired shape with highest precision. In addition, the die bearing section helps the control frictional condition for homogenized metal flow.

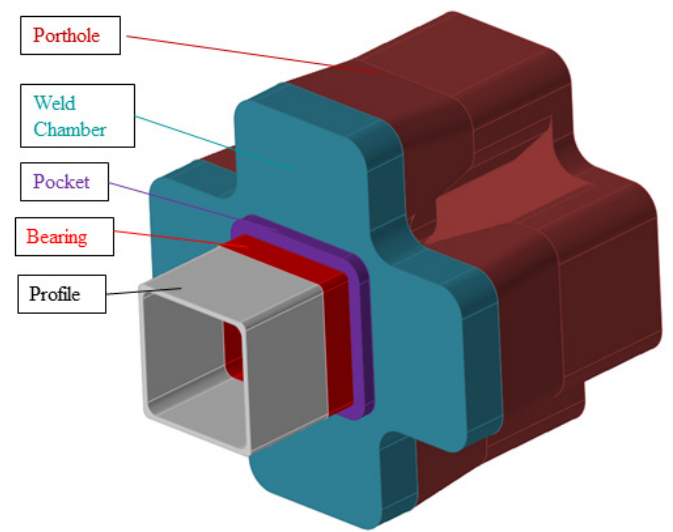

Fig. 2. A detailed explanation of sections for extrusion porthole die

\section{Results and discussions}

The model was built in a commercial CAD software and it was uploaded to HyperXtrude Inspire Extrude Metal 2019 software. The simulation for the proposed model was carried out with a workstation with two Intel Xeon CPU (E5645)-2.40 GHz processors. The obtained results were given in Figs. 3-6.

The Fig. 3 shows the pressure distribution for the different steps of the process. The process was divided into four stages according to the punch stroke. At the first phase of the extrusion, the pressure value at the portholes was calculated around $270 \mathrm{MPa}$. However, at the final phase, the pressure was about $382 \mathrm{MPa}$. It could be observed that the pressure distribution of the pocket section and on the profile is homogenous and stable for entire process. It results that product can be obtained with high precision.

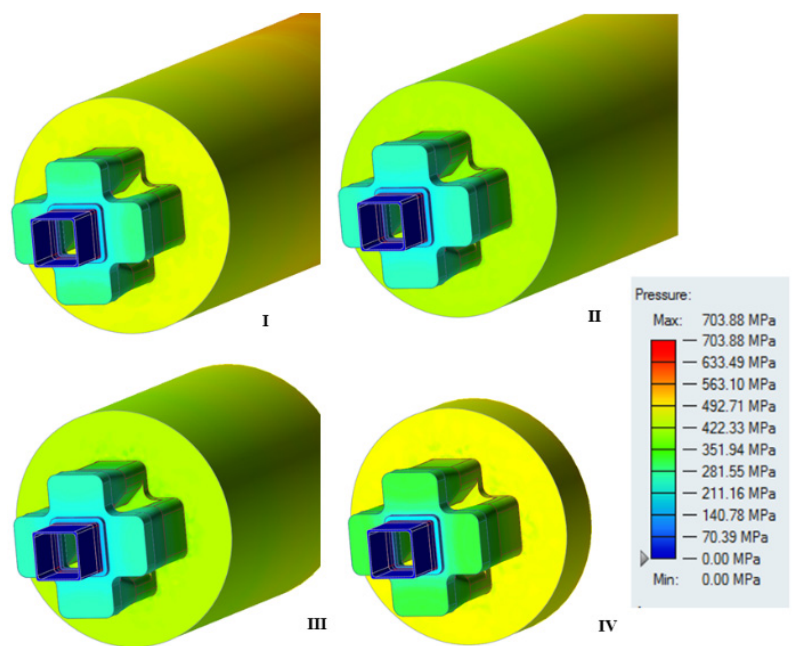

Fig. 3. Pressure distribution of the extrusion process

The Fig. 4 gives the temperature distribution of the process. The temperature distribution is an important parameter for extrusion process when the porthole die was used for the final product. The temperature distribution also effects the welding quality of the product. Rapid changes in the 
temperature and inhomogeneous temperature distribution lead to undesirable welding lines on the surface of the product. The both should be foreseen and be avoided at the die design phase. The process starts at $450{ }^{\circ} \mathrm{C}$ and at the end of the first phase of the process, the calculated temperature at the profile was $563{ }^{\circ} \mathrm{C}$. At the end of the process, the calculated value at the profile was $582{ }^{\circ} \mathrm{C}$. When the temperature in the welding chamber was examined, it could be observed that the calculated temperature is in the range of $500-525^{\circ} \mathrm{C}$ at the beginning of the process, while these values are in the range of $517-541^{\circ} \mathrm{C}$ at the end of the process.

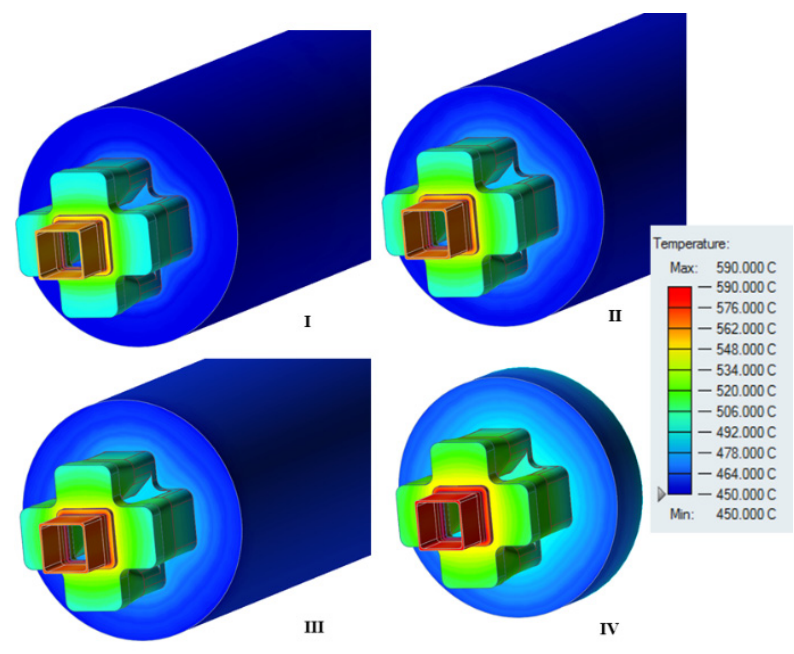

Fig. 4. Temperature distribution of the extrusion process
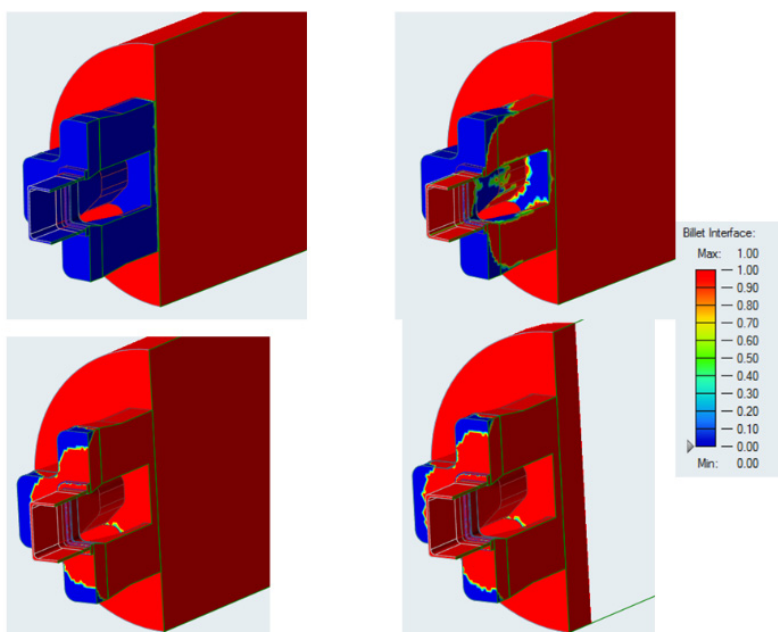

Fig. 5. Billet interface analysis of the extrusion process

Extrusion is a continuous process and so, more than one billet according to the customer order could be used during the production. Therefore, each billet should be weld to each other otherwise there would be tracks on the surface of the product as an extrusion defect. To eliminate this fault, the billet interface analysis could be used as a tool to estimate bonding quality of the billets. The billet interface analysis is given in Fig. 5. The blue color on the scale bar represents the old billet and red color represents the new one. At the beginning of the process (upper left), the new billet is about to enter the die. When the punch moves, the new billet enters the porthole and exits from the die as a product at the end of the first quarter of the process. The results show that there is no 
discontinuity on the profile surface or interface.

Fig. 6 gives the analysis of relative exit speed difference. This analysis is used for estimating the deformation and flow of the material during the extrusion in detail. The distortion on the profile and flow discontinuities could be predicted by using the results of this analysis. Especially, material flow is needed to be homogenous and this analysis gives the differences of the flow speed of the material from the average value. The die design could be reconsidered to recover the frictional surfaces of the die with the results of this analysis. It can be seen from the figure that exit speed of the profile is homogenous and almost is the same for the every point on the main metal stream. It can be concluded from the figure that there is no distortion on the profile and the product could be precisely extruded. At the porthole and welding chamber sections, the main metal stream is seen as blue color. There is a small disturbances at the metal flow which is on the entrance of the bearing surfaces and that turbulence on the flow is the result of the balancing the metal flow by controlling the friction on the bearing surface.

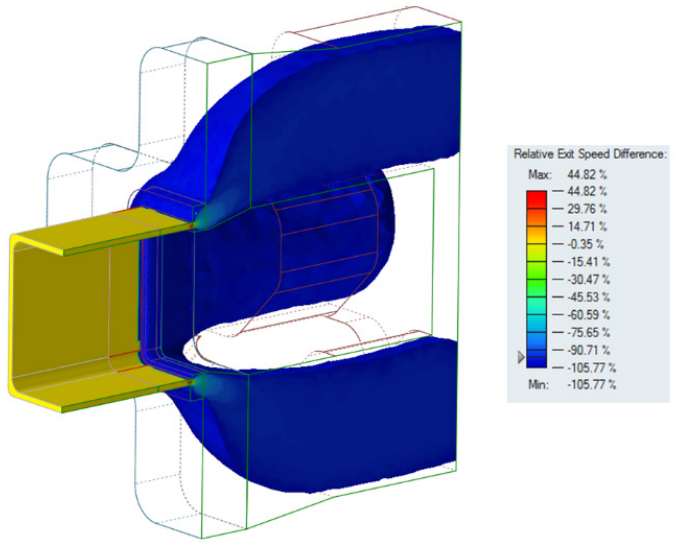

Fig. 6. Relative exit speed difference

\section{Conclusions}

In order to investigate the extrusion process of a standard structural box profile, finite element method based software was used for the study. The change on the main process parameters which effects the product quality was investigated. The following conclusions were drawn:

The pressure distribution was evaluated for the extrusion process. It could be observed that the pressure distribution of the pocket section and on the profile is homogenous and stable for entire process which means that product could be formed with high precision.

The maximum temperature was calculated as $582{ }^{\circ} \mathrm{C}$. The temperature range reached in the welding chamber was between $517-541^{\circ} \mathrm{C}$. The main welding mechanism between stream welds is solid state bonding. It can be concluded that calculated temperature values are suitable for a desired welding conditions during the process.

The research shows that the product quality and dimensional accuracy would be satisfactory after evaluating the outcomes of the FEM study.

\section{Acknowledgements}

The HyperXtrude Inspire Extrude Metal 2019 software was provided by the project supported by the Dicle University with Grant No: MUHENDISLIK.15.011.

Authors also wish to thank eksenAL Aluminum Extrusion Die Factory for their support. 


\section{References}

[1] Yu J., Zhao G., Cui W., Zhang C., Chen L. Microstructural evolution and mechanical properties of welding seams in aluminum alloy profiles extruded by a porthole die under different billet heating temperatures and extrusion speeds. Journal of Materials Processing Technology, Vol. 247, 2017, p. 214-222.

[2] Yu J., Zhao G., Cui W., Chen L., Chen X. Evaluating the welding quality of longitudinal welds in a hollow profile manufactured by porthole die extrusion: experiments and simulation. Journal of Manufacturing Processes, Vol. 38, 2019, p. 502-515.

[3] Yu J., Zhao G. Study on the welding quality in the porthole die extrusion process of aluminum alloy profiles. Procedia Engineering, Vol. 207, 2017, p. 401-406.

[4] Yu J., Zhao G., Chen L. Analysis of longitudinal weld seam defects and investigation of solid-state bonding criteria in porthole die extrusion process of aluminum alloy profiles. Journal of Materials Processing Technology, Vol. 237, 2016, p. 31-47.

[5] Yu J., Zhao G. Interfacial structure and bonding mechanism of weld seams during porthole die extrusion of aluminum alloy profiles. Materials Characterization, Vol. 138, 2018, p. 56-66.

[6] Edwards S. P., Den Bakker A. J., Zhou J., Katgerman L. Physical simulation of longitudinal weld seam formation during extrusion to produce hollow aluminum profiles. Materials and Manufacturing Processes, Vol. 24, 2009, p. 409-421.

[7] Yi J., Hu Wang Z., Wen Liu Z., Ming Zhang J., He X. FE analysis of extrusion defect and optimization of metal flow in porthole die for complex hollow aluminium profile. Transactions of Nonferrous Metals Society of China, Vol. 28, 2018, p. 2094-2101.

[8] Qamar S. Z., Pervez T., Chekotu J. C. Die defects and die corrections in metal extrusion. Metals (Basel), Vol. 8, Issue 6, 2018, p. 380.

[9] Liu Z., Li L., Li S., Yi J., Wang G. Simulation analysis of porthole die extrusion process and die structure modifications for an aluminum profile with high length-width ratio and small cavity. Materials (Basel), Vol. 11, 2018, p. E1517. 